\title{
Relação entre solo e haste sulcadora de semeadora em Latossolo escarificado em diferentes épocas
}

\author{
David Peres da Rosa ${ }^{(1)}$, José Miguel Reichert ${ }^{(1)}$, Arcenio Sattler ${ }^{(2)}$, Dalvan José Reinert(1), \\ Marcelo Ivan Mentges ${ }^{(1)}$ e Davi Alexandre Vieira ${ }^{(1)}$
}

\begin{abstract}
(1)Universidade Federal de Santa Maria, Centro de Ciências Rurais, Departamento de Solos, Av. Roraima, no 1.000, CEP 97105-900 Santa Maria, RS.E-mail: david.dpr@gmail.com,reichert@smail.ufsm.br, dalvan@smail.ufsm.br, marcelomentges@gmail.com, daviperigoti@yahoo.com.br (2)Embrapa Trigo, Caixa Postal 451, CEP 99001-970 Passo Fundo, RS. E-mail: arcenio@cnpt.embrapa.br
\end{abstract}

\begin{abstract}
Resumo - O objetivo deste estudo foi avaliar a duração dos efeitos da escarificação em Latossolo Vermelho argiloso, pelo estudo da relação entre solo e haste sulcadora de semeadora. Os tratamentos foram: solo sob semeadura direta há 13 anos; solo escarificado há quatro anos (2001); solo escarificado há dois anos (2003); e solo escarificado há seis meses (2005), todos com ou sem tráfego de máquinas agrícolas. Dados de esforço vertical, momento associado à haste sulcadora, área de solo efetivamente mobilizada, resistência específica operacional, macroporosidade, microporosidade, porosidade total e densidade do solo foram coletados, e o esforço de tração na haste sulcadora foi calculado. A demanda de esforços aumentou com o incremento no decurso do tempo de execução da escarificação, e o solo escarificado há seis meses apresentou a menor demanda. O solo escarificado há quatro anos apresentou comportamento similar ao solo sob semeadura direta, e ofereceu a menor área mobilizada e a maior resistência operacional. Nos parâmetros físicos, diferenças foram observadas apenas na camada $0-0,10 \mathrm{~m}$, onde o solo recém escarificado apresentou a maior macroporosidade, e menor microporosidade e densidade do solo. Após quatro anos, não se evidenciou mais o efeito da escarificação na relação entre solo e haste sulcadora.
\end{abstract}

Termos para indexação: compactação do solo, resistência específica operacional, semeadura direta, solo argiloso.

\section{Soil and planter shank relation in an Oxisol chiseled at different times}

\begin{abstract}
The objective of this study was to evaluate the chiseling effect duration in an Oxisol, based on the study of soil and planter shank relation. The treatments were: no-till for 13 years; four years since chiseling (2001); two years since chiseling (2002); and six months since chiseling (2005), where all treatments were submitted or not to traffic with agricultural machinery. Data about vertical force and moment associated to: shank, soil mobilized area, specific operational resistance, macroporosity, microporosity, total porosity and soil density, were collected, and draught on shank was calculated. Increasing of time since chiseling required increasing of the forces, and six months since chiseling showed the smallest demand. Four years since chiseling had similar behavior to the no-till treatment, resulting in the smallest soil mobilized area and the greatest operational resistance. Physical property differences occurred only in layer $0-0.10 \mathrm{~m}$, and recent chiseling showed the greatest soil macroporosity, and the smallest soil microporosity and bulk density. After four years, chiseling effect was not found on soil-planter shank relations.
\end{abstract}

Index terms: soil compaction, specific operational resistance, no-tillage, clay soils.

\section{Introdução}

Alguns solos sob semeadura direta, na região do planalto médio do Rio Grande do Sul, encontram-se com elevado grau de compactação, que tem se agravado pelo não revolvimento (restrito à linha de semeadura) e, também, pela intensidade com que as operações agrícolas foram implementadas no passado, com o sistema de preparo convencional do solo. Alterações estruturais na camada arável do solo, em decorrência de atividades agrícolas, têm sido relatadas: redução na macroporosidade, porosidade total e da estabilidade de agregados; aumento da resistência à penetração; diminuição da infiltração e do volume de água disponível às plantas (Denardin, 1992; Barcelos et al., 1999).

A implantação do sistema de semeadura direta tem sido feita sem a correção desses problemas, na confiança de que a cobertura vegetal e o abandono das mobilizações 
de solo constituem, por si só, uma solução (Denardin \& Kochhann, 1993). Problemas estruturais do solo, remanescentes do sistema de preparo convencional, são expressos principalmente pela presença da compactação do solo. Contudo, mesmo em solo em que a implantação da semeadura direta tenha sido feita após a correção desses problemas, a compactação do solo pode ocorrer após algum tempo, a depender do seu manejo.

A escarificação é comumente recomendada para solos com problemas de compactação e gera alguns benefícios imediatos, resultantes da ruptura de camadas compactadas ou adensadas (Botta et al., 2006), o que facilita a penetração das raízes das culturas e a infiltração da água para camadas mais profundas do solo. Além desses benefícios, Camara \& Klein (2005) adicionam a vantagem da redução das perdas de solo ao se manterem parcialmente incorporados à superfície do solo consideráveis quantidades de restos culturais.

Contudo, a duração dos efeitos da escarificação no solo não é claramente conhecida. A duração dos benefícios da escarificação, em Latossolo Vermelho sob semeadura direta, chega até a 10 meses após o preparo, segundo Secco \& Reinert (1997), e proporciona melhor porosidade total e maior rugosidade superficial. Mahl et al. (2004), no entanto, depois de 18 meses, não encontraram mais efeito da escarificação em Nitossolo Vermelho, nos parâmetros de força de tração, potência na barra de tração, consumo de combustível e capacidade de campo efetiva. Botta et al. (2006), ao investigar a duração da ação do escarificador no solo, relataram que esse implemento possui um efeito de redução imediata dos problemas oriundos da compactação. Porém, após dois anos de realização da escarificação, numa profundidade de trabalho de $0,28 \mathrm{~m}$, com intensidade de tráfego maior que $95 \mathrm{Mg} \mathrm{km} \mathrm{ha}{ }^{-1}$, houve uma recompactação na camada de 0,30-0,60 m. Esses autores concluíram que a frequiência da ação desse implemento deve ser de uma vez a cada dois anos.

Pela avaliação do comportamento dos esforços requeridos na haste sulcadora da semeadora, tem-se uma maneira de avaliar a duração dessa prática. Nesse sentido, Bortolotto et al. (2006) encontraram esforço de tração de 2,34 kN com velocidade de $4,74 \mathrm{~km} \mathrm{~h}^{-1}$, em Latossolo Vermelho distrófico, sob semeadura direta há oito anos, com umidade de $0,14 \mathrm{~kg} \mathrm{~kg}^{-1}$. Em Argissolo Vermelho distrófico sob semeadura direta, Cepik et al. (2005) encontraram valores menores que $1,15 \mathrm{kN}$ por linha, em semeadora adubadora de precisão com cinco linhas, com sulcador facão, a $4,5 \mathrm{~km} \mathrm{~h}^{-1} \mathrm{em}$ solo com $0,17 \mathrm{~kg} \mathrm{~kg}^{-1}$ de umidade.

A disponibilidade de informações relativas à caracterização da escarificação pode ajudar a reduzir os impactos da atividade agrícola sobre o solo. A tecnologia disponível para diminuir o problema da compactação restringe-se ao uso de implementos agrícolas que mobilizam o solo em profundidade ligeiramente maior que o limite inferior da camada compactada, associado ao cultivo subseqüente de espécies vegetais de elevada produção de biomassa e elevada densidade de raízes (Kochhann et al., 2000).

O objetivo deste trabalho foi avaliar a duração da escarificação no solo e seu efeito no desempenho da haste sulcadora de semeadora em solo argiloso.

\section{Material e Métodos}

As coletas das informações se iniciaram em 2005, em um Latossolo Vermelho distrófico (Embrapa, 2006), durante a semeadura da soja numa área experimental da Embrapa Trigo, a $28^{\circ} 10^{\prime} \mathrm{S}$ e $52^{\circ} 22^{\prime} \mathrm{W}$, a aproximadamente $686 \mathrm{~m}$ de altitude.

O local apresenta ocorrência de precipitação pluvial mínima de $60 \mathrm{~mm}$ mensais, ao longo de todos os meses do ano (Nimer, 1989), e o clima da região se enquadra na classificação de Köppen, zonas Cfa e Cfb.

O delineamento empregado foi o de blocos ao acaso, em arranjo fatorial $4 \times 2$ - solo sob semeadura direta, em quatro épocas após a escarificação, e dois níveis de tráfego - com três repetições. Os tratamentos utilizados foram: solo escarificado no verão de 2001, sem tráfego; solo escarificado no verão de 2001, com tráfego; solo escarificado no inverno de 2003, sem tráfego; solo escarificado no inverno de 2003, com tráfego; solo escarificado no inverno de 2005, sem tráfego; solo escarificado no inverno de 2005, com tráfego; solo sob sistema de semeadura direta há 13 anos, sem tráfego há seis anos (o tráfego controlado foi implementado no ano 2000); e solo sob semeadura direta há 13 anos, com tráfego há seis anos, como testemunhas.

O experimento foi implantado no ano de 2000, sob tráfego controlado: o maquinário utilizado para as tarefas agrícolas trafegava sempre no mesmo trajeto. Assim, as parcelas $(6 \times 12 \mathrm{~m})$ possuíam regiões de alto tráfego e de ausência deste. Para tal, foram utilizadas barras delimitadoras horizontais na frente do trator para 
guiá-lo de forma que a ponta delas ficasse margeando a parcela experimental. Dessa forma, o trator, ou a colhedora, operaram sempre no mesmo trajeto.

Os locais de coleta das amostras foram: solo com tráfego - ponto de coleta a $0,10 \mathrm{~m}$ da lateral externa de onde passavam os pneus do maquinário; solo sem tráfego - coleta realizada onde havia ausência de tráfego de máquinas agrícolas (entre os locais de tráfego).

O escarificador empregado foi um Jumbo de cinco hastes parabólicas, com ponteira estreita, espaçadas em $0,34 \mathrm{~m}$, marca JAN, que trabalhou a $0,25 \mathrm{~m}$ de profundidade, com um rolo destorroador, desenvolvido pela Embrapa Trigo, acoplado.

A semeadura foi executada com auxílio de uma semeadora Semeato SHM 11/13, com quatro linhas espaçadas em $0,50 \mathrm{~m}$, com sulcador tipo disco desencontrado (ressalta-se que todas as linhas tinham a mesma configuração).

Para as operações agrícolas, foi utilizado um trator MF275 com 47,80 kW de potência no motor, sem tração dianteira auxiliar, com peso $2,665 \mathrm{Mg}$, com pneus dianteiros Goodyear 7,5-16(R1) com pressão de inflação $165,47 \mathrm{kPa}$ e pneus traseiros Firestone 14,9-28(R1) com $124,11 \mathrm{kPa}$ (a pressão foi escolhida em função da deflexão apresentada pelo pneu no campo).

Para analisar a duração do efeito da escarificação no solo, coletaram-se informações acerca do esforço de tração $\left(\mathrm{F}_{\mathrm{T}}\right)$, esforço vertical $\left(\mathrm{F}_{\mathrm{V}}\right)$ e momento associado $\left(\mathrm{M}_{\mathrm{O}}\right)$ à haste sulcadora da semeadora. Os dados de esforços foram obtidos com auxílio de um anel octogonal, ligado a um módulo de aquisição de dados. $\mathrm{O}$ anel foi responsável pela leitura do esforço horizontal, vertical e momento associado à haste sulcadora e, o módulo de aquisição de dados foi responsável pela alimentação das pontes extensiométricas presentes no anel octogonal e por condicionar, filtrar e armazenar os dados. $\mathrm{O}$ anel foi instalado entre uma estrutura tipo carrinho portaferramentas e o sulcador, conforme Godwin (1975). O sulcador, tipo facão, atuou à profundidade média de $0,13 \mathrm{~m}$, à velocidade de $3,2 \mathrm{~km} \mathrm{~h}^{-1}$, com umidade do solo de $0,36 \mathrm{~kg} \mathrm{~kg}^{-1}$.

As especificações técnicas do anel são: material de aço 4340; capacidade nominal de $8 \mathrm{kN}$ de força vertical, $20 \mathrm{kN}$ de força horizontal e momento de $13 \mathrm{kN} \mathrm{m}$. Esse anel foi desenvolvido pelo Laboratório de Instrumentação e Eletrônica da Universidade Estadual de Campinas. $\mathrm{O}$ anel foi configurado para uma taxa de aquisição de 20 dados por segundo $(20 \mathrm{~Hz})$.

Outros parâmetros relacionados ao desempenho da haste sulcadora também foram mensurados como indicadores do tempo de permanência do efeito da escarificação no solo, área mobilizada e porosidade do solo.

$\mathrm{O}$ requerimento de força de tração por volume de solo mobilizado, denominado resistência específica operacional, foi determinado conforme a equação:

$\mathrm{R}_{\mathrm{e}}=\mathrm{F}_{\mathrm{m}} / \mathrm{V}_{\mathrm{m}}$,

em que: $R_{e}$ é a resistência específica operacional $\left(\mathrm{kN} \mathrm{m}^{-3}\right) ; \mathrm{F}_{\mathrm{m}}$ é a força de tração média $(\mathrm{kN})$; e $\mathrm{V}_{\mathrm{m}}$ é o volume médio mobilizado de solo $\left(\mathrm{m}^{3}\right)$.

O volume médio mobilizado de solo foi obtido pela medição da área da seção transversal do solo efetivamente mobilizado, por meio da metodologia do trapézio, após a multiplicação por $1 \mathrm{~m}$ de avanço na direção de trabalho. Para tal, mediram-se, perpendicularmente à linha de trabalho, as profundidades até onde a haste sulcadora conseguiu mobilizar o solo e, então, retirou-se todo o solo mobilizado transversalmente. Em cada tratamento, retirou-se a camada de solo invertida e efetuou-se a limpeza da área mobilizada, tomando-se três seções, e adotando-se a média do cálculo da área de solo mobilizada, com o uso da equação seguinte (Serpa \& Magalhães, 1997):

$\mathrm{A}_{\mathrm{m}}=\left(\mathrm{s}+\mathrm{w}_{\mathrm{p}}\right) \mathrm{d}$,

em que: $\mathrm{A}_{\mathrm{m}}$ é a área mobilizada de solo $\left(\mathrm{m}^{2}\right)$; s é a distância lateral de ruptura (m); $\mathrm{w}_{\mathrm{p}}$ é a largura do sulco (m); e d é a profundidade do sulco (m).

Para a determinação da macroporosidade, microporosidade, porosidade total e densidade do solo, foram realizadas coletas em campo, com cilindros de aço inoxidável de $0,06 \mathrm{~m}$ de diâmetro e $0,05 \mathrm{~m}$ de altura, realizadas em três pontos aleatórios ao longo da parcela. Em cada ponto, foi realizada uma coleta por camada $(0,00-0,10 \mathrm{~m}, \quad 0,10-0,20 \mathrm{~m}$ e $0,20-0,30 \mathrm{~m})$. Em laboratório, as amostras foram saturadas por capilaridade durante 24 horas e, posteriormente, foram pesadas e levadas à mesa de tensão, onde foram submetidas à tensão de sucção de $6 \mathrm{kPa}$, até que se 
estabelecesse o equilíbrio entre a água retida na amostra e a sucção aplicada. Posteriormente, pesaram-se novamente as amostras e, então, foram encaminhadas para estufa a $105-110^{\circ} \mathrm{C}$ (Embrapa, 1997).

A análise estatística, para os dados de esforços, constou de análise da variância e comparação de médias pelo teste de Tukey, a 5 e $1 \%$ de probabilidade, executadas pelo programa ESTAT (Barbosa et al., 1992).

\section{Resultados e Discussão}

Os esforços de tração $\left(\mathrm{F}_{\mathrm{T}}\right)$ e esforços verticais $\left(\mathrm{F}_{\mathrm{V}}\right)$, nos tratamentos estão ilustrados na Figura 1. O comportamento dos esforços foi similar nas condições com ou sem tráfego. $\mathrm{O} \mathrm{F}_{\mathrm{T}}$ cresceu com o aumento no período da realização da escarificação. O solo escarificado em 2001, sob ação do tráfego, apresentou a maior demanda de esforço de tração (Figura 1).

$\mathrm{O}$ tráfego ocasionou um pequeno deslocamento da média no $\mathrm{F}_{\mathrm{T}}$ e $\mathrm{F}_{\mathrm{V}}$ (Figura 1) e demonstrou maior variação entre o quartil superior e o quartil inferior. Isso corrobora o fato de que as tensões transmitidas pela borda do pneu do trator agrícola propiciam uma variação estrutural ao solo, expressa pelo aumento da resistência interna do solo, a qual influenciou a demanda de esforços. Segundo Abu-Hamdeh \& Reeder (2003), após a passagem de um pneu agrícola, a propagação da tensão no solo gera a formação de bulbos com resistências volumétricas diferentes, o que ocasiona estrutura física diferenciada e conseqüente variação nos esforços demandados para mobilização.

Contrariamente à baixa demanda de tração observada neste trabalho no solo escarificado recentemente (inverno de 2005), Furlani et al. (2004) encontraram comportamento oposto em um Nitossolo recém-escarificado que exigiu maior demanda de tração que o solo sob semeadura direta. Contudo, Mahl et al. (2004) não encontraram diferença em Nitossolo sob semeadura direta e solo escarificado há 18 meses.

Para o $\mathrm{F}_{\mathrm{T}}$, o solo sob semeadura direta apresentou comportamento similar ao solo escarificado em 2003, e demonstrou a menor variação entre o quartil superior e o inferior. Isso aponta para duas hipóteses: (i) maior qualidade estrutural do solo, com homogeneidade em seus agregados ou (ii) estado de compactação elevado,

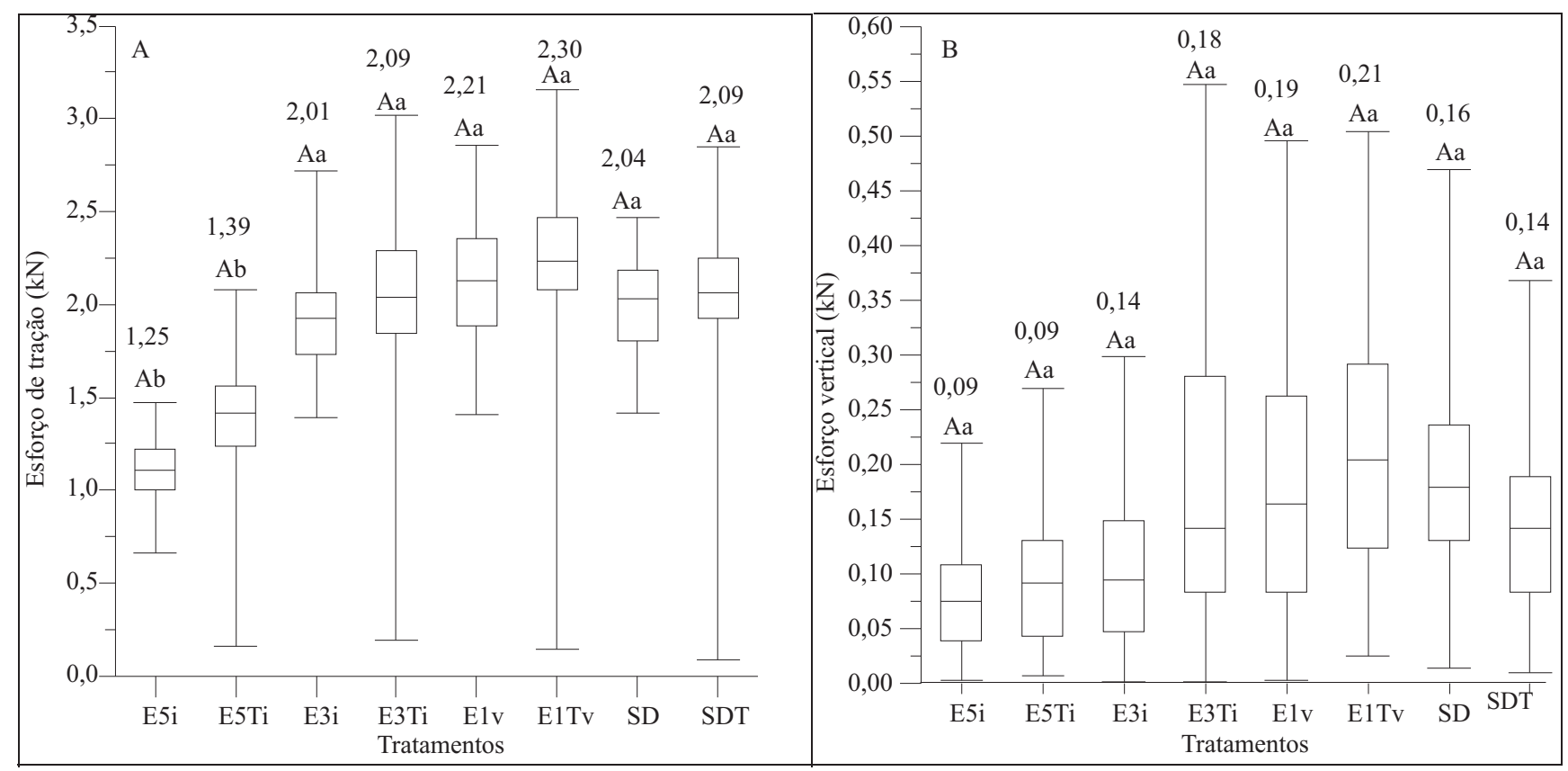

Figura 1. Média e percentis dos esforços de tração (A) e dos esforços verticais (B). Médias de tratamentos com letras iguais maiúsculas não diferem entre si quanto ao efeito de tráfego dentro de um mesmo tratamento, enquanto médias de tratamentos com letras iguais minúsculas não diferem entre os tratamentos, dentro de uma mesma condição de tráfego, pelo teste de Tukey, a 5\% de probabilidade. E1, E3 e E5: solos escarificados, respectivamente nos anos 2001, 2003 e 2005. SD: solo sob semeadura direta, sem escarificação. T: tratametno com tráfego. v e i: escarificação realizada no verão ou no inverno, respectivamente. 
o qual confere ao solo uma condição massiva devido à ruptura dos agregados (Larson et al., 1980).

A estrutura física do solo, uma das responsáveis pela dinâmica da interação da haste sulcadora com o solo, não gerou movimento rotacional na haste, constatado pelos dados de momento associado ao mecanismo sulcador, que se manteve constante em $3,11 \mathrm{kN} \mathrm{m}$.

Os dados de área de solo mobilizado e resistência específica operacional dos tratamentos estão dispostos na Tabela 1. Embora os resultados não tenham apresentado diferenças estatisticamente significativas, pôde-se observar a seguinte tendência: sem ação do tráfego, a maior mobilização de solo foi observada no tratamento escarificado em 2005, e a menor no escarificado em 2001. Ao se adicionar o efeito do tráfego, o solo escarificado em 2003 apresentou o maior incremento na área mobilizada, e os demais apresentaram redução dessa variável. A redução na área mobilizada é resultado da ação de compactação resultante do tráfego de máquinas agrícolas. Godwin (2007) relata que o movimento do solo com a ação de ferramentas verticais estreitas ocorre de forma ascendente; sendo assim, com o solo compactado, a resultante de forças internas de ruptura tende a ser reduzida, o que gera redução da área mobilizada.

O solo escarificado há quatro anos também demandou o maior esforço de tração por área trabalhada, expresso pelos dados de resistência específica operacional, o que

Tabela 1. Área de solo mobilizado e resistência específica operacional nos tratamentos em estudo.

\begin{tabular}{lccccc}
\hline Tratamento & \multicolumn{2}{c}{ Área mobilizada $\left(\mathrm{m}^{2}\right)$} & & \multicolumn{2}{c}{$\begin{array}{c}\text { Resistência específica } \\
\text { operacional }\left(\mathrm{kN} \mathrm{m}^{-3}\right)\end{array}$} \\
\cline { 2 - 3 } \cline { 5 - 6 } & Sem tráfego & Com tráfego & & Sem tráfego & Com tráfego \\
\hline Semeadura direta & 0,0095 & 0,0089 & & 209,58 & 235,20 \\
Escarificado 2001 & 0,0086 & 0,0072 & & 247,96 & 319,36 \\
Escarificado 2003 & 0,0094 & 0,0106 & & 205,61 & 196,71 \\
Escarificado 2005 & 0,0126 & 0,0092 & & 88,05 & 151,31 \\
\hline
\end{tabular}

resulta em um aumento na demanda de potência ao trator. Tal fato pode desencadear um sério problema, já que, conforme Casão Júnior et al. (1998), é comum o trator não possuir reserva de torque suficiente para o serviço de semeadura, o que aumenta o consumo de combustível e a patinagem do trator e resulta em maior compactação do solo.

O solo escarificado há seis meses, independentemente do tráfego, apresentou menor resistência específica, pois sua estrutura estava mais enfraquecida, em razão da recente mobilização, o que gerou uma redução na energia consumida pelo sulcador e incremento na área mobilizada.

Os dados de macroporosidade, microporosidade, porosidade total e densidade do solo nas camadas em estudo, constam da Tabela 2. Na camada superficial, o solo escarificado há quatro anos apresentou a menor macroporosidade $(8,40 \%)$, microporosidade $(37,45 \%) \mathrm{e}$ a maior densidade $\left(1,44 \mathrm{Mg} \mathrm{m}^{-3}\right)$, o que demonstra seu elevado estado de consolidação e pode explicar a alta demanda de esforços nele observadas. A ação da escarificação pode ser observada no solo escarificado recentemente e, além desse tratamento haver proporcionado o menor esforço de tração, propiciou também a menor microporosidade $(33,18 \%)$ e densidade $\left(1,20 \mathrm{Mg} \mathrm{m}^{-3}\right)$, e a maior macroporosidade $(17,81 \%) \mathrm{e}$ porosidade total $(52,62 \%)$ do solo na camada superficial, o que lhe conferiu uma estrutura com menor efeito da compactação.

Nas demais camadas, não houve diferença entre os tratamentos nas propriedades físicas, exceto na camada de $0,20-0,30 \mathrm{~m}$, em que o solo sob semeadura direta sem tráfego apresentou menor densidade que o escarificado em 2003. Isso poderia indicar uma possível compactação subsuperficial causada pela haste escarificadora nesse solo argiloso, à semelhança da

Tabela 2. Médias de macroporosidade (Ma), microporosidade (Mi), porosidade total (Pt) e densidade do solo (Ds) dos tratamentos, nas três camadas em estudo ${ }^{(1)}$.

\begin{tabular}{|c|c|c|c|c|c|c|c|c|c|c|c|c|}
\hline \multirow[t]{2}{*}{ Manejo (M) } & \multicolumn{4}{|c|}{ Camada $0,00-0,10 \mathrm{~m}$} & \multicolumn{4}{|c|}{ Camada $0,10-0,20 \mathrm{~m}$} & \multicolumn{4}{|c|}{ Camada $0,20-0,30 \mathrm{~m}$} \\
\hline & Ma & $\begin{array}{c}\mathrm{Mi} \\
-(\%)----- \\
\end{array}$ & Pt & $\begin{array}{c}\text { Ds } \\
\left(\mathrm{Mg} \mathrm{m}^{-3}\right)\end{array}$ & Мa & $\begin{array}{c}\mathrm{Mi} \\
-(\%)--\end{array}$ & $\begin{array}{c}\mathrm{Pt} \\
---- \\
\end{array}$ & $\begin{array}{c}\text { Ds } \\
\left(\mathrm{Mg} \mathrm{m}^{-3}\right)\end{array}$ & $\mathrm{Ma}$ & $\begin{array}{c}\mathrm{Mi} \\
-(\%)---\end{array}$ & Pt & $\begin{array}{c}\text { Ds } \\
\left(\mathrm{Mg} \mathrm{m}^{-3}\right)\end{array}$ \\
\hline SD & $10,05 b$ & $37,28 \mathrm{a}$ & $47,33 b$ & $1,41 \mathrm{a}$ & $9,01 \mathrm{a}$ & $36,47 a$ & $45,48 \mathrm{a}$ & $1,41 \mathrm{a}$ & $12,35 a$ & $38,48 \mathrm{a}$ & $50,83 a$ & $1,29 b$ \\
\hline $\mathrm{E} 1_{\mathrm{v}}$ & $8,40 \mathrm{~b}$ & $37,45 \mathrm{a}$ & $45,85 b$ & $1,44 \mathrm{a}$ & $9,19 \mathrm{a}$ & $37,44 a$ & $46,63 a$ & $1,43 \mathrm{a}$ & $9,27 \mathrm{a}$ & $38,03 \mathrm{a}$ & $47,30 \mathrm{ab}$ & $1,36 \mathrm{ab}$ \\
\hline $\mathrm{E} 3_{\mathrm{i}}$ & $12,77 b$ & $35,78 \mathrm{ab}$ & $48,54 b$ & $1,34 \mathrm{a}$ & $9,25 \mathrm{a}$ & $36,48 \mathrm{a}$ & $45,73 a$ & $1,45 \mathrm{a}$ & $9,00 \mathrm{a}$ & $37,52 \mathrm{a}$ & $46,52 b$ & $1,42 \mathrm{a}$ \\
\hline $\mathrm{E} 5_{\mathrm{i}}$ & $17,81 \mathrm{a}$ & $33,18 b$ & $52,62 \mathrm{a}$ & $1,20 \mathrm{~b}$ & $12,30 \mathrm{a}$ & $34,99 \mathrm{a}$ & $47,30 \mathrm{a}$ & $1,34 \mathrm{a}$ & $10,29 a$ & $38,24 \mathrm{a}$ & $48,44 \mathrm{ab}$ & $1,32 \mathrm{ab}$ \\
\hline \multicolumn{13}{|l|}{ Tráfego $(\mathrm{T})$} \\
\hline Sem & $12,80 \mathrm{a}$ & $36,42 \mathrm{a}$ & $49,22 \mathrm{a}$ & $1,35 \mathrm{a}$ & $9,81 \mathrm{a}$ & $36,67 \mathrm{a}$ & $46,49 \mathrm{a}$ & $1,41 \mathrm{a}$ & $10,48 \mathrm{a}$ & $38,02 \mathrm{a}$ & $48,46 a$ & $1,36 \mathrm{a}$ \\
\hline Com & $11,72 \mathrm{a}$ & $35,42 \mathrm{a}$ & $47,95 \mathrm{a}$ & $1,35 \mathrm{a}$ & $10,06 \mathrm{a}$ & $36,02 \mathrm{a}$ & $46,08 \mathrm{a}$ & $1,41 \mathrm{a}$ & $9,96 a$ & $38,12 \mathrm{a}$ & $48,08 \mathrm{a}$ & $1,34 \mathrm{a}$ \\
\hline CV (\%) & 24,03 & 5,98 & 4,86 & 5,95 & 23,60 & 4,15 & 3,99 & 5,60 & 22,04 & 2,27 & 4,97 & 5,02 \\
\hline
\end{tabular}

${ }^{(1)}$ Médias seguidas por letras iguais não diferem entre si pelo teste de Tukey, a 5\% de probabilidade; SD: semeadura direta; E1 E3 ${ }_{\mathrm{i}}$ : escarificado em 2003; E5 i $_{\mathrm{i}}$ escarificado em 2005. 
formação de pé-de-arado ou de grade (Silva et al., 2003); contudo, maiores estudos são necessários para investigar essa possibilidade.

\section{Conclusões}

1. A demanda de esforços solicitados pela haste sulcadora aumenta com o tempo transcorrido desde a realização da escarificação e, após quatro anos, não se observa mais o efeito da escarificação no solo.

2. A escarificação é mais eficiente no aumento da macroporosidade na camada superficial do solo, e decresce com o aumento do tempo desde a realização da escarificação.

3. O efeito da escarificação nas propriedades físicas do solo e na demanda de tração dura de dois a quatro anos.

\section{Agradecimentos}

À Embrapa Trigo, por permitir o uso de sua área experimental para realização deste trabalho; aos pesquisadores Rainoldo Alberto Kochhann e José Eloir Denardin, da Embrapa Trigo, pela coordenação do projeto e apoio técnico e financeiro para a execução deste trabalho.

\section{Referências}

ABU-HAMDEH, N.H.; REEDER, R.C. Measuring and predicting stress distribution under tractive devices in undisturbed soils. Biosystems Engineering, v.85, p.493-502, 2003.

BARBOSA, J.C.; MALHEIROS, E.B.; BANZATTO, D.A. ESTAT: um sistema de análises estatísticas de ensaios agronômicos. Jaboticabal: Unesp, 1992. Versão 2.0.

BARCELOS, A.A.; CASSOL, E.A.; DENARDIN, J.E. Infiltração de água em um Latossolo Vermelho-Escuro sob condições de chuva intensa em diferentes sistemas de manejo. Revista Brasileira de Ciência do Solo, v.23, p.35-43, 1999.

BORTOLOTTO, V.C.; PINHEIRO NETO, R.; BORTOLOTTO, M.C. Demanda energética de uma semeadora-adubadora para soja sob diferentes velocidades de deslocamento e coberturas do solo. Engenharia Agrícola, v.26, p.122-130, 2006.

BOTTA, G.F.; JORAJURIA, D.; BALBUENA, R.; RESSIA, M.; FERRERO, C.; ROSATTO, H.; TOURN, M. Deep tillage and traffic effects on subsoil compaction and sunflower (Helianthus annus L.) yields. Soil and Tillage Research, v.1, p.164-172, 2006.

CAMARA, R.K.; KLEIN, V.A. Propriedades físico-hídricas do solo sob plantio direto escarificado e rendimento da soja. Ciência Rural, v.35, p.813-819, 2005.

CASÃO JÚNIOR, R.; ARAÚJO, A.G.; RALISCH, R.; SILVA, A.L.; LADEIRA, A.S.; SILVA, J.C.; MACHADO, P.; ROSSETO, R.
Avaliação do desempenho da semeadora-adubadora Magnum 2850 em plantio direto no basalto paranaense. Londrina: Iapar, 1998. 47p. (Circular Iapar, 105).

CEPIK, C.T.C.; TREIN, C.R.; LEVIEN, R. Força de tração e volume de solo mobilizado por haste sulcadora em semeadura direta sobre campo nativo, em função do teor de água no solo, profundidade e velocidade de operação. Engenharia Agrícola, v.25, p.447-457, 2005.

DENARDIN, J.E. Solo: constituição e degradação. In: MARCANTONIO, G. (Org.). Solos e irrigação. Porto Alegre: UFRGS, 1992. p.13-28.

DENARDIN, J.E.; KOCHHANN, R.A. Requisitos para a implantação e manutenção do sistema plantio direto. In: EMBRAPA. Centro Nacional de Pesquisa de Trigo. Plantio direto no Brasil. Passo Fundo: Aldeia Norte, 1993. p.19-27.

EMBRAPA. Manual de métodos de análise de solos. 2.ed. Rio de Janeiro: Embrapa-CNPS, 1997. 212p.

EMBRAPA. Sistema brasileiro de classificação de solos. 2.ed. Rio de Janeiro: Embrapa Solos, 2006. 306p.

FURLANI, C.E.A.; GAMERO, C.A.; LEVIEN, R.; LOPES, A.; SILVA, R.P. da. Desempenho operacional de uma semeadoraadubadora de precisão, em função do preparo do solo e do manejo da cobertura de inverno. Engenharia Agrícola, v.24, p.388-395, 2004.

GODWIN, R.J. A review of the effect of implement geometry on soil failure and implement forces. Soil and Tillage Research, v.97, p.331-340, 2007.

GODWIN, R.J. An extended octagonal ring transducer for use in tillage studies. Journal of Agricultural Engineering Research, v.20, p.347-352, 1975.

KOCHHANN, R.A.; DENARDIN, J.E.; BERTON, A.L. Compactação e descompactação de solos. Passo Fundo: Embrapa Trigo, 2000. 20p. (Embrapa Trigo. Documentos, 19).

LARSON, W.E.; GUPTA, S.C.; USECE, R.A. Compression of agricultural soils from eight soil orders. Soil Science Society of America Journal, v.44, p.450-457, 1980.

MAHL, D.; GAMERO, C.A.; BENEZ, S.H.; FURLANI, C.E.A.; SILVA, A.R.B. Demanda energética e eficiência da distribuição de sementes de milho sob variação de velocidade e condição de solo. Engenharia Agrícola, v.24, p.150-157, 2004.

NIMER, E. Climatologia do Brasil. 2.ed. Rio de Janeiro: IBGE, 1989. 442p.

SECCO, D.; REINERT, D.J. Efeitos imediato e residual de escarificadores em Latossolo Vermelho-Escuro sob plantio direto. Engenharia Agrícola, v.16, p.52-61, 1997.

SERPA, F.M.; MAGALHÃES, P.S.G. Estimativa de esforços em ferramentas estreitas para o preparo de solos. Engenharia Agrícola, v.17, p.62-73, 1997.

SILVA, R.B.; DIAS JÚNIOR, M.S.; SANTOS, F.L.; FRANZ, C.A.B. Influência do preparo inicial sobre a estrutura do solo quando da adoção do sistema plantio direto, avaliada por meio da pressão de preconsolidação. Revista Brasileira de Ciência do Solo, v.27, p.961-971, 2003. 